\title{
Sweeper's lung disease: a cross-sectional study of an overlooked illness among sweepers of Pakistan
}

This article was published in the following Dove Press journal:

International Journal of COPD

16 April 2013

Number of times this article has been viewed

\section{Shaikh Khurshid Anwar \\ Naeem Mehmood \\ Nasir Nasim \\ Maryam Khurshid \\ Bilal Khurshid}

Department of Pulmonary Medicine, Pakistan Institute of Medical Sciences (PIMS), Islamabad, Pakistan

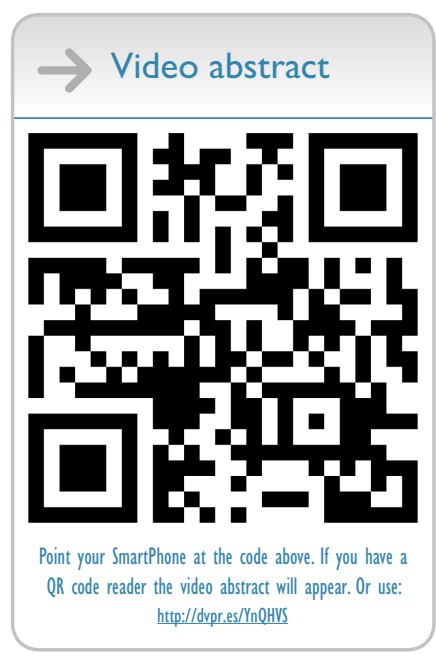

Correspondence: Shaikh Khurshid Anwar Department of Pulmonary Medicine, Pakistan Institute of Medical Sciences (PIMS), Post Box 4600,

Islamabad, Pakistan

Tel +92 5I 5704555

Fax +925I 5706998

Email dr.khurshid@hotmail.co.uk
Background: Sweepers are prone to develop chronic obstructive pulmonary disease even without tobacco smoking.

Purpose: To investigate roadside dust as a cause of air flow obstruction among sweepers, and the role of spirometry in its preclinical diagnosis.

Material and methods: One-hundred nonsmoking sweepers (aged 30-60 years) of both sexes sweeping on roads for 8-12 hours a day for the Capital Development Authority of Islamabad, Pakistan were used as study participants (Group A). One-hundred healthy nonsmokers (aged 30-60 years) in the same socioeconomic group and living in the same environment represented the nonsweeper group (Group B). After proper clinical evaluation and chest X-rays, spirometric evaluation was carried out in both groups. Comparisons were drawn between various spirometric parameters.

Results: Pulmonary function tests showed that the mean forced vital capacity was $78 \pm 1.40$ in the sweeper group (Group A) and $83 \pm 0.86$ in the nonsweeper group (Group B). Mean forced expiratory volume in 1 second was $66 \pm 1.67$ in Group A and $85 \pm 0.85$ in Group B $(P<0.05)$, a difference of $19 \%$. The forced midexpiratory flow was $41 \%$ lower in Group A than in Group $\mathrm{B}(P<0.0001)$. The pattern of pulmonary function obstruction was shown to be proportional to the duration of exposure to dust caused by sweeping.

Conclusion: Occupational exposure to dust leads to an obstructive pattern among sweepers. Spirometry is the simplest, noninvasive technique to detect preclinical disease.

Keywords: COPD, sweepers, dust, spirometry

\section{Introduction}

Chronic obstructive pulmonary disease (COPD) is a common, progressively disabling, and often fatal condition found all over the world. The exact prevalence of COPD in Pakistan is not known, but a large number of patients attend outpatient and emergency departments across most of the country. The socioeconomic burden of COPD is considerable. Apart from smoking, urban air pollution is an important cause of COPD.

COPD can be divided into two major categories. The reducing type, such as that found in London, consists mainly of carbonaceous particulate matter and sulfur dioxide. The oxidizing form, such as that found in the Los Angeles area, consists mainly of primary pollutants (hydrocarbons and the oxides of nitrogen) and photochemical reaction pollutants (ozone, nitrogen oxide, aldehydes, peroxyacetyl nitrate, and other organic nitrates). ${ }^{1}$ Although a sudden increase in levels of air pollution, such as that which occurs with smog, can result in increased morbidity and mortality in patients 
with established $\mathrm{COPD}^{2}$ or asthma, there is little evidence that urban air pollution per se causes COPD in nonsmokers. ${ }^{3}$ However, urban air pollution appears to play an additional role to that of cigarette smoke in the pathogenesis of COPD, and may be partly responsible for the progression of disability in already affected patients. Epidemiological studies have revealed a higher incidence of chronic bronchitis among urban dwellers, implying that air pollution in cities is responsible for the increased incidence of respiratory illnesses found in urban environments. ${ }^{4}$ Occupational regulations protecting the health of sweepers in most developing countries are seldom found; similarly, precautions (eg, wearing protective masks) are seldom taken by these workers during their working hours. They dry sweep on roads for $>8$ hours daily, and are thus exposed to large amounts of dust, predisposing them to the development of respiratory illnesses and COPD. No studies appear to be available on the subject, therefore prompting this study to be undertaken in Islamabad, Pakistan to determine whether dust is a predisposing factor for COPD among sweepers.

\section{Material and methods}

In this study, the sweepers (employees of the Capital Development Authority of Islamabad) who were dry sweeping on the roads in the city of Islamabad were evaluated for airway obstruction. Of the 130 study subjects initially examined, 30 were excluded for various reasons (20 were smokers, five showed cardiomegaly on chest X-ray, and five had a history of underlying lung disease). A total of 100 sweepers of both sexes (aged 30-60 years) with a history of exposure to dust of $>5$ years' duration were selected for the study (Group A) and 100 healthy nonsmoker individuals of both sexes (aged 30-60 years) from the same socioeconomic group (eg, shopkeepers, security guards, laborers) were selected as the nonsweeper group (Group B). Each of these individuals had lived in Islamabad for $>5$ years. In addition, they were shown to be free from any cardiopulmonary ailment. Well-informed consent was obtained from subjects in both groups. The study also had the approval of the Institutional Ethical Committee.

Based on a questioner, a medical history was taken and a physical examination conducted. This consisted of a chest radiograph (posteroanterior view), and spirometry was performed on each individual in each group using a Vitalograph ${ }^{\circledR}$ with pulmonary function test printer (Vitalograph Ltd, Buckingham, UK). Group A was then divided into three groups based on age as well as the duration of their exposure to dust-Group I: 30-39 years of age $(n=57)$; Group II: 40-49 years of age $(n=25)$; and Group III: $50-60$ years of age $(n=18)$. Comparisons of various pulmonary functions were then made between Group A (sweepers) and Group B (nonsweepers). Three spirograms that met the standard criteria of acceptability were recorded. ${ }^{5,6}$

\section{Statistical analysis}

The data were analyzed using SPSS version 13 (SPSS Inc, Chicago, IL, USA). The chi-squared test was used for categorical variables and Student's $t$-test was used for continuous variables with normal distribution. The MannWhitney $U$ test and the Wilcoxon signed-rank test were used to compare nonparametric continuous variables. The relationship of various spirometric parameters between cases and controls were compared. $P<0.05$ was considered significant.

\section{Results}

The mean forced vital capacity (FVC) was $78 \pm 1.40$ in Group A (sweepers) and $83 \pm 0.86$ in Group B (nonsweepers) (Tables 1 and 2).

The mean forced expiratory volume in 1 second $\left(\mathrm{FEV}_{1}\right)$ was $66 \pm 1.67$ in Group A and $85 \pm 0.85$ in Group B. The $\mathrm{FEV}_{1}$ was $19 \%$ lower in Group A. Study subjects in Group A with a mean exposure to dust of 10 years showed mild airway obstruction. The $\mathrm{FEV}_{1} / \mathrm{FVC}$ ratio (measured) was $14.5 \%$ lower in Group A.

The percent predicted value of $\mathrm{FEV}_{1} / \mathrm{FVC}$ was $13 \%$ lower in Group A. The mean forced midexpiratory flow (FMEF) was $53 \pm 1.98$ in Group A and $94 \pm 1.91$ in Group B. The mean FMEF was significantly lower in Group A $(41 \%$; $P<0.0001)$. The mean FMEF/FVC ratio in Group A was $65 \pm 2.24$ and $102 \pm 2.02$ in Group B. These mean values are shown in Tables 1 and 2.

Table I Results of pulmonary function tests in Group A (sweepers)

\begin{tabular}{lcccc}
\hline $\begin{array}{l}\text { Spirometric } \\
\text { indices }\end{array}$ & $\begin{array}{l}\text { Total } \\
(\mathbf{n}=100)\end{array}$ & $\begin{array}{l}\text { Male } \\
(\mathbf{n}=\mathbf{5 5})\end{array}$ & $\begin{array}{l}\text { Female } \\
(\mathbf{n}=\mathbf{4 5})\end{array}$ & P-value \\
\hline FVC (\% predicted) & $78 \pm 1.40$ & $80 \pm 2.0$ & $76 \pm 1.74$ & $>0.05$ \\
FEV, (\% predicted) & $66 \pm 1.67$ & $68 \pm 2.40$ & $63 \pm 2.10$ & $>0.05$ \\
FEV,/FVC ratio & $71.5 \pm 1.29$ & $70 \pm 1.64$ & $73 \pm 2.01$ & $>0.05$ \\
(measured) & & & & \\
FEV,/FVC & $-13 \pm 1.26$ & $-14 \pm 1.60$ & $-12 \pm 2.01$ & $>0.05$ \\
FMEF & $53 \pm 1.98$ & $52 \pm 2.75$ & $53 \pm 2.8 \mathrm{I}$ & $>0.05$ \\
FMEF/FVC ratio & $65 \pm 2.24$ & $58 \pm 2.44$ & $73 \pm 3.68$ & $<0.00 \mathrm{I}$ \\
PEF (\% predicted) & $43 \pm 1.96$ & $42 \pm 2.74$ & $43 \pm 2.8 \mathrm{I}$ & $>0.05$ \\
\hline
\end{tabular}

Notes: Data represents mean \pm standard error; -13 means that the measured value is $13 \%$ below the predicted value.

Abbreviations: $\mathrm{FEV}_{1}$, forced expiratory volume in I second; FMEF, forced midexpiratory flow; FVC, forced vital capacity; PEF, peak expiratory flow. 
Table 2 Results of pulmonary function tests in Group B (nonsweepers)

\begin{tabular}{lcccc}
\hline $\begin{array}{l}\text { Spirometric } \\
\text { indices }\end{array}$ & $\begin{array}{l}\text { Total } \\
(\mathbf{n}=100)\end{array}$ & $\begin{array}{l}\text { Male } \\
(\mathbf{n}=\mathbf{5 6})\end{array}$ & $\begin{array}{l}\text { Female } \\
(\mathbf{n = 4 4 )}\end{array}$ & P-value \\
\hline FVC (\% predicted) & $83 \pm 0.86$ & $83 \pm 0.93$ & $83 \pm 1.25$ & $>0.05$ \\
FEV (\% predicted) & $85 \pm 0.85$ & $85 \pm 0.92$ & $84 \pm 0.91$ & $>0.05$ \\
FEV/FVC\% & $86 \pm 0.37$ & $85 \pm 0.40$ & $85 \pm 0.64$ & $>0.05$ \\
(measured) & & & & \\
FEV/FVC\% & $+2 \pm 0.36$ & $+2 \pm 0.38$ & $1.12 \pm 0.89$ & $>0.05$ \\
(\% predicted) & & & & \\
FMEF (\% predicted) & $94 \pm 1.91$ & $94 \pm 2.04$ & $92.5 \pm 2.84$ & $>0.05$ \\
FMEF/FVC ratio & $102 \pm 2.02$ & $103 \pm 2.1$ & $97 \pm 3.27$ & $>0.05$ \\
PEF (\% predicted) & $74 \pm 1.8$ & $75 \pm 1.9$ & $68 \pm 4.37$ & $>0.05$ \\
\hline
\end{tabular}

Note: Data represents mean \pm standard error.

Abbreviations: $\mathrm{FEV}_{1}$, forced expiratory volume in I second; FMEF, forced midexpiratory flow; FVC, forced vital capacity; PEF, peak expiratory flow.

There was a significant difference in the spirometric parameters between the two groups.

Chest X-ray evaluation revealed that nine subjects showed evidence of COPD in the form of increased bronchovascular markings and thickened bronchial walls (five subjects) and hyperinflation (four subjects). The rest of the subjects had normal chest X-ray results. Study subjects (sweepers) were analyzed according to their symptoms, ie, cough with expectoration and shortness of breath. A linear relationship between exposure to dust and COPD symptoms was evident, as shown in Table 3.

\section{Discussion}

Environment plays a critical role in the development of COPD. Respiratory problems as an occupational hazard in a variety of professions have been studied by a number of researchers, ${ }^{7-10}$ but there is limited data in the English medical literature on the topic of dust as a nonindustrial occupational hazard among sweepers. This cross-sectional study focused on sweepers who were exposed to dust for prolonged periods during their working hours. There are no occupational health and safety regulations for sweepers in underdeveloped countries like Pakistan, and since sweepers do not use masks or other protective equipment during working hours, they are exposed to the potential hazards of dust. A comparison of various spirometry parameters was made between a group of sweepers and nonsweepers living in the same area. Spirometric values were observed to be significantly lower among sweepers, thus implying that inhalation of dust in street sweepers is a significant occupational hazard. Cases that had a mean duration of 10 years' exposure to nonindustrial dust, according to the criteria of Braun for grading the impairment of respiratory function, ${ }^{11}$ had mild

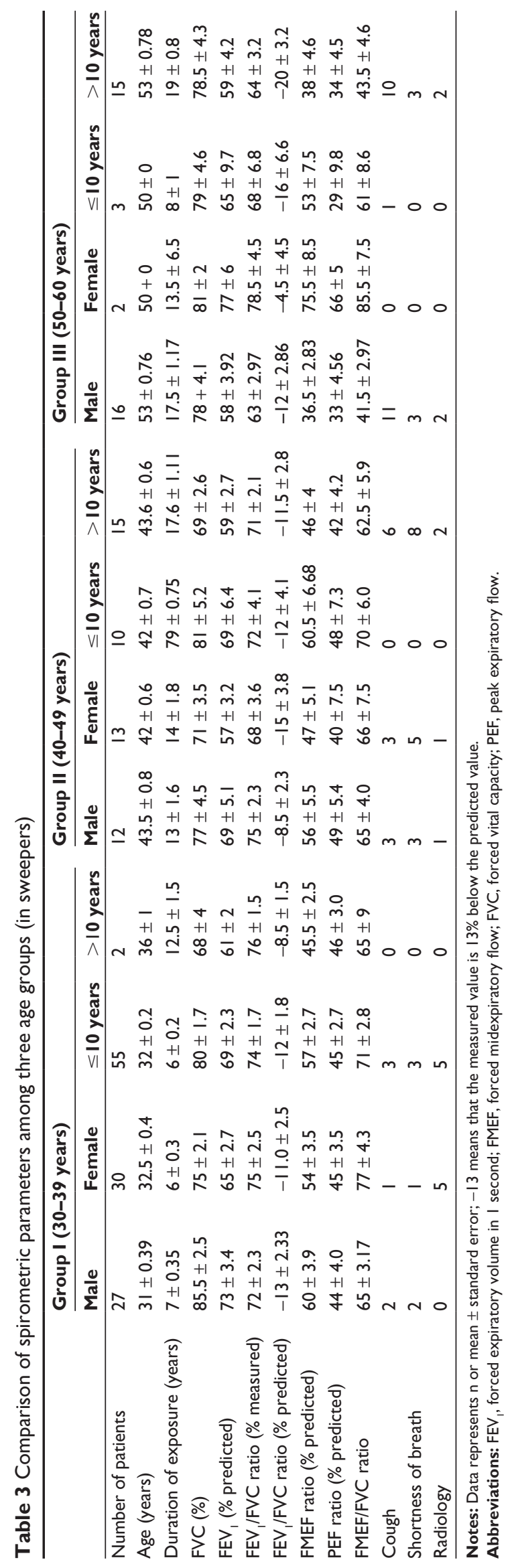


airway obstruction. Concomitantly, the $\mathrm{FEV}_{1} / \mathrm{FVC}$ ratio was also significantly lower in this group (Table 1). This means that all the cases had mild airflow obstruction according to the criteria of Fahey. ${ }^{12}$ A linear relationship between development of obstructive airway disease and duration of exposure to dust was shown. Subjects with exposure to dust for $>17$ years were symptomatic, and had significant airway obstruction. In contrast to this, no subject in Group B (nonsweepers) living in the same environment displayed the same symptoms. However, it is possible that the appearance of clinical signs could lag behind symptomatology. Similar conclusions were made by Morgan and Reger, who showed that people working in dusty atmospheres in various occupations showed an increased prevalence of cough and sputum production. ${ }^{13}$ The current study shows conclusively that exposure of $>10$ years duration to nonindustrial dust can be sufficient to cause a moderate degree of airflow obstruction as defined by Fraser et al without clinical signs. ${ }^{14}$

The current study also demonstrated that spirometry is a very important diagnostic tool for preclinical diagnosis. The data showed that FMEF was significantly lower $(P<0.00001)$ in Group A than in Group B, indicating small airway disease. It is at this point, before development of COPD, that removal of these workers from an environment harmful to them, as well as the adoption of other means to reduce their exposure to dust, would be beneficial. These findings should be an eye opener for public health planners and warrant regular health assessment of these workers, together with the provision of necessary precautionary measures, eg, masks, in addition to regular spirometric evaluation.

There have been many attempts in the past to correlate occupational exposure to the development of COPD. Kuhn and Askin studied a random sample of 8515 adults from the Midwest and Eastern US; they found that subjects who had been exposed to dust, gases, and fumes showed a significantly increased incidence of respiratory disease and airflow obstruction $\left(\mathrm{FEV}_{1} / \mathrm{FVC}\right.$ ratio $\left.<0.6\right) .{ }^{15}$ No element of fibrosis was found in the current study (based on the spirometric parameters and chest radiographs, eg, proportional reduction in $\mathrm{FEV}_{1}$ and $\mathrm{FVC}$ with normal/ supernormal ratio of $\mathrm{FEV}_{1} / \mathrm{FVC}$ ). An explanation for the variation may be related to particle size and deposition patterns. For example, large particles tend to impact on the airway and cause airflow obstruction, whereas smaller particles reach alveolar airspaces where they induce fibrosis and a restrictive ventilatory pattern. ${ }^{16}$ Individuals who are exposed to nonindustrial dust for $>10$ years could further be evaluated for hypoxia by means of serial arterial blood gas analysis. This may also be helpful in Pakistan for evaluation of cor pulmonale in younger age groups.

\section{Conclusion}

In conclusion, this study reveals that the long and continued inhalation of nonindustrial dust is an important factor in the development of the symptoms of COPD among sweepers as shown in their obstructive spirometric patterns. The conclusions drawn from this study impose great responsibility on health services and employers to adopt measures to reduce morbidity in this poor population. Furthermore, it has been shown that spirometry is the single most important as well as the simplest, cheapest, and noninvasive technique aiding in the detection of preclinical cases before the development of sweeper's lung disease.

\section{Disclosure}

The authors report no conflicts of interest in this work.

\section{References}

1. Cohen A, Miraldi F. Imaging in chronic obstructive pulmonary disease. In: Cherniack NS, editor. Chronic Obstructive Pulmonary Disease, 1st ed. Philadelphia, PA: WB Saunders; 1991:386-407.

2. Bates DV. The fate of the chronic bronchitic: a report of the ten-year follow-up in the Canadian Department of Veterans'Affairs coordinated study of chronic bronchitis. Am Rev Respir Dis. 1973;108(5): 1043-1065.

3. Zapletal A, Jech J, Paul T, Samanek M. Pulmonary function studies in children living in an air-polluted area. Am Rev Respir Dis. 1973;107(3): 400-409.

4. Donahoe M, Rogers RM. Laboratory evaluation of the patient with chronic obstructive pulmonary disease. In: Cherniack NS, editor. Chronic Obstructive Pulmonary Disease, 1st ed. Philadelphia, PA: WB Saunders; 1991:373-383.

5. Gardner RM. Standardization of spirometry: a summary of recommendations from the American Thoracic Society. The 1987 update. Ann Intern Med. 1988;108(2):217-220.

6. Huijsmans RJ, de Haan A, ten Hacken NN, Straver RV, van't Hul AJ. The clinical utility of the GOLD classification of COPD disease severity in pulmonary rehabilitation. Respir Med. 2008;102(1):162-171.

7. Soyseth V, Boe J, Kongerud J. Relation between decline in FEV and exposure to dust and tobacco smoke in aluminium potroom workers. Occup Environ Med. 1997;54(1):27-31.

8. Hunting KL, Welch LS. Occupational exposure to dust and lung disease among sheet metal workers. Br J Ind Med. 1993;50(5):432-442.

9. Miller BG, MacCalman L. Cause-specific mortality in British coal workers and exposure to respirable dust and quartz. Occup Environ Med. 2010;67(4):270-276.

10. Soyseth V, Johnsen HL, Bugge MD, Hetland SM, Kongerud J. Prevalence of airflow limitation among employees in Norwegian smelters: a longitudinal study. Occup Environ Med. 2011;68(1):24-29.

11. Braun SR. Chronic obstructive pulmonary disease. In: Braun SR, editor. Concise Textbook of Pulmonary Medicine. New York, NY: Elsevier Science; 1989:104-120.

12. Fahey PJ. Clinical utility of pulmonary function testing. Pulmonary Clinical Update. 1985;1:1-8.

13. Morgan WKC, Reger RB. Chronic airflow limitation and occupation. In: Cherniack NS, editor. Chronic Obstructive Pulmonary Disease, 1st ed. Philadelphia, PA: WB Saunders; 1991:270-285. 
14. Fraser RG, Pare JAP, Pare PD, Fraser RS, Genereux GP. Chronic obstructive pulmonary disease. In: Fraser RG, Pare JAP, Pare PD, Fraser RS, Genereux GP, editors. Diagnosis of Diseases of the Chest, 3rd ed. Philadelphia, PA: WB Saunders; 1990:2087-2186.

15. Kuhn C, Askin FB. Lung and mediastinum. In: Kissane JM, Anderson WAD, editors. Anderson's Pathology, 8th ed. St Louis, MO: CV Mosby; 1985:898-907.
16. Rabe KF, Hurd S, Anzueto A, et al. Global strategy for the diagnosis, management, and prevention of chronic obstructive pulmonary disease: GOLD executive summary. Am J Respir Crit Care Med. 2007;176(6): $532-555$.

International Journal of COPD

\section{Publish your work in this journal}

The International Journal of COPD is an international, peer-reviewed journal of therapeutics and pharmacology focusing on concise rapid reporting of clinical studies and reviews in COPD. Special focus is given to the pathophysiological processes underlying the disease, intervention programs, patient focused education, and self management protocols.

\section{Dovepress}

This journal is indexed on PubMed Central, MedLine and CAS. The manuscript management system is completely online and includes a very quick and fair peer-review system, which is all easy to use. Visit http://www.dovepress.com/testimonials.php to read real quotes from published authors.

Submit your manuscript here: http://www.dovepress.com/international-journal-of-copd-journal 